\title{
Multiscale Laboratory Study and Numerical Analysis of Water-Weakening Effect on Shale
}

\author{
Zhen Li $\mathbb{D}^{1},{ }^{1}$ Shangge Liu, ${ }^{2}$ Wentao Ren, ${ }^{3}$ Jinjin Fang $\left(\mathbb{D},{ }^{1}\right.$ Qinghua Zhu, ${ }^{4}$ and Zhilin Dun \\ ${ }^{1}$ School of Civil Engineering, Henan Polytechnic University, Jiaozuo 454003, China \\ ${ }^{2}$ CCCC Second Highway Consultants Co., Ltd., Wuhan 430056, China \\ ${ }^{3}$ Tangkou Coal Mining Company Ltd., Jining 272055, China \\ ${ }^{4}$ School of Foreign Studies, Henan Polytechnic University, Jiaozuo 454003, China \\ Correspondence should be addressed to Zhen Li; zhenli@hpu.edu.cn
}

Received 31 July 2019; Revised 17 March 2020; Accepted 20 April 2020; Published 11 May 2020

Academic Editor: Charles C. Sorrell

Copyright $\odot 2020$ Zhen Li et al. This is an open access article distributed under the Creative Commons Attribution License, which permits unrestricted use, distribution, and reproduction in any medium, provided the original work is properly cited.

\begin{abstract}
Water-weakening effect is one of the most important factors inducing large deformation and stability problems of shale strata in the Huangjiazhai Tunnel. The influence of water on shale with various water contents and its mechanism still needs more study. In this paper, the X-ray diffraction and water absorption test were first conducted to determine the influence of mineral components on water-rock interaction. Then, a series of rock mechanical tests, including uniaxial compressive test, Brazilian disk test, and triaxial compressive test, were carried out on shale under dried condition, wetted condition with various water contents, and saturated condition. For the uniaxial compression, tension, and triaxial compression, the softening coefficient could reach 0.38 , 0.63 , and 0.52 , respectively. Based on the macroscale experiments, a numerical case study of tunnel excavation was investigated to evaluate the water effect. Finally, with the aid of scanning electron microscope and failure morphology, the mechanism of waterweakening effect on shale was discussed from microscopic and macroscopic perspectives. The thickness of the double layer increases with the increase of water immersion time. This paper provides a set of useful data for reference in construction in shale strata, and a methodology to evaluate water-weakening effect through laboratory and numerical modelling approaches.
\end{abstract}

\section{Introduction}

In rock engineering, there are external factors influencing the construction process, such as stress state $[1-3]$ and stress path [4], temperature [5-7], and water. In these factors, water is generally regarded as a disadvantage in construction. Water plays a significant role in the mechanical properties of underground surrounding rocks and the development of landslide hazard [8]. Therefore, water poses a great threat to the stability in rock engineering applications. It is recognized that evaluation of the water-weakening effect is a key to engineering classification and project design [9].

The water-weakening effect has been well studied in different types of rocks on their strength and stiffness. Colback and Wild [10] found that the uniaxial strength of saturated sandstone is nearly the half of the dried samples. Vásárhelyi [11] reported a $74 \%$ reduction in uniaxial compressive strength of the Miocene limestone and 53\% reduction in modulus due to saturation. Similarly, Rajabzadeh et al. [12] and Gajic et al. [13] reported a 70\% and 10\% reduction in uniaxial compressive strength of carbonate rocks and limestones due to saturation, respectively. Mann and Fatt [14] conducted a series of compression tests on sandstones and found that modulus could be reduced by $6 \sim 19 \%$ for the saturated samples. To investigate the effect of water on tensile strength, Brazilian tests $[15,16]$, uniaxial tension tests [17], and point loading tests [18] have been performed. Ojo and Brook [18] and Karakul and Ulusay [19] reported that the tensile strength of saturated sandstone could be reduced by around $60 \%$. Parate [20] studied the effect of water on limestone and attributed the strength loss to a reduction in the cohesive strength. Bell [21] proposed that the strength reduction is related to the porosity change. Hua et al. [22] used Brazilian test to study the fracture mechanical properties under periodic water-rock interactions. Dyke and Dobereiner [23] believe that the bond 
cohesion in sandstones is influenced by water. Burshtein [24] also observed a structure change to reduce elastic modulus in the saturated sandstone. Li et al. [8] studied the water effect on chlorite schist and applied grouting test. In former research studies, sandstone and limestone have been studied extensively.

The mechanical properties of shale are usually focused in the field of oil/gas industry. Over $75 \%$ of the drilled formations are made up of shale, and over $70 \%$ of the borehole problems are caused by shale instability [25]. The stability is related to the shale intrinsic properties and the drilling fluid. Shale is a kind of clay-rich sedimentary rock and expands during adsorbing liquids or gas [26]. So shale properties are extremely sensitive to water. Jumikis [27] found that the compressive strength of saturated shale was one order of magnitude lower than that of the dry samples. Gutierrez et al. [28], Silva et al. [29], and Lin et al. [30] revealed that a number of wetting cycles dissolved the clay minerals and decreased the strength of shale. Chen et al. [31-33] studied the fracture mechanical properties of shales under the effect of water, salinity, $\mathrm{pH}$, and temperature. Considering the water-weakening on shale, a better understanding of strength reduction by water under uniaxial compressive, triaxial compressive, and tensile stress condition needs to be explored in depth.

The excavation of the Huangjiazhai Tunnel of Ma-Zhu Expressway in northwest Hubei Province in Central China revealed a shale formation. The average buried depth is about $250 \mathrm{~m}$. Site visit shows the underground strata is rich in water in the form of dripping or linear seepage. There is a lot of rainfall in this area, which enriches the water content in the strata. Under water wet condition, the shale is classified as soft rock of green gray colour, medium weathering, muddy, and fine laminated structure with developed fissures. The joint surfaces are filled with clay and cuttings. The thickness of each rock layer is $0.1 \sim 0.5 \mathrm{~m}$ with muddy cementations. The degree of bonding between the structural surfaces is poor, which results in the weak integrity of the surrounding rocks. In this case, deformation rate of the surrounding rock increases during tunnel excavation. Figure 1 shows the vault crown settlement of the right tube at the stake of YK61 +810 . The accumulated crown settlement increases with monitoring time. The settlement rate increases rapidly at the first 5 days and slows down in the next 25 days approximately. The settlement rate increases again thereafter, and there is no trend towards stability after monitoring for 40 days. Consequently, shale in Huangjiazhai Tunnel has outstanding large deformation due to the effect of water weakening.

To service for engineering design of Huangjiazhai Tunnel, Zheng et al. [34] conducted uniaxial test under water immersion. More tests are still needed. Based on the study, in this paper, the X-ray diffraction (XRD) and water absorption test were first conducted to determine the influence of mineral components on water-rock interaction. Then, a series of rock mechanical tests, including uniaxial compressive test, Brazilian disk test, and triaxial compressive tests, were carried out on shale under natural condition, wetted condition with various water contents, and water condition. Based on the macroscale experiments, a numerical case study of tunnel excavation was investigated to evaluate the water effect. Finally, with the aid of scanning electron microscope (SEM) and failure morphology, the mechanism of water-weakening effect on shale was discussed from microscopic and macroscopic perspectives.

\section{Test Materials and Methods}

2.1. Materials. Rock cores were taken from Silurian Longmaxi Formation shale in Huangjiazhai Tunnel. To quantify mineral components with aid of X-ray diffraction (XRD), the shale samples were triturated to powder with a diameter of $10 \mu \mathrm{m}$ approximately. XRD was conducted on the D8 Advance $\mathrm{X}$-ray diffractometer. The scanning angle and velocity are $3^{\circ}-50^{\circ}$ and $5^{\circ} / \mathrm{min}$. Test result of one specimen is listed in Figure 2. It suggests that chlorite and muscovite contribute to more than half of the total components. The two clay minerals are sensitive to water $[35,36]$. Like other clay minerals, their special crystal structure can produce weak expansion under water immersion. Inspired by Chen et al. [32], crystalline swelling and osmotic swelling were used to describe clay swelling mechanism. Crystalline swelling is a stepwise process with the formation of multiple integer layers of hydrates, which could occur in all types of clay minerals. Osmotic swelling is driven by cation concentration differences between interlayer space and surrounding water, causing water diffusion into interlayer space to restore balance. Osmotic swelling is limited to clay minerals with exchangeable interlayer cations such as smectite. So the water-weakening effect in shales could be contributed primarily to the crystalline swelling. For example of chlorite schist, its unit cell consists of two layers, namely, brucite layer and mica-like layer. Due to the weak hydrogen bond connection between the two layers, water molecules enter the unit cell and expand the interlayer distance.

In this study, the samples used for uniaxial and triaxial test were made into cylinder with a diameter of $50 \mathrm{~mm}$ and a height of $100 \mathrm{~mm}$. To minimize the anisotropy effect, the shale sample was made as standard cylinder sample with its axis parallel to the vertical bedding planes. Three kinds of samples were used: dried sample, saturated sample, and water immersed sample. Dried samples were prepared by drying process in the oven for 24 hours. Parts of the dried samples were chosen for preparing the saturated and immersed samples. The saturated samples were obtained by immersing the dried samples in a vacuum space and then filled with water. In order to study the behavior of shale affected by water immersion, shale samples were put in water for various times and immersed samples were prepared. Figure 3 shows the water absorption response of shale. The water content is defined as the ratio of water weight to solid weight. The water content increases rapidly with immersion time in the first few days, then slows down, and tends to keep constant. After 90 days of water immersion, the samples could be viewed as saturated samples. The data could be fitted well in a power function. The natural water content of shale samples is about $0.1 \%$. The saturated water absorption of samples is about $1.1 \%$. The result shows that shale has a 


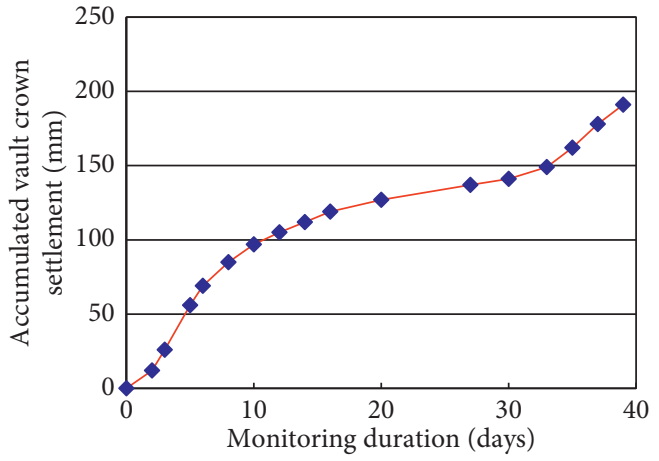

(a)

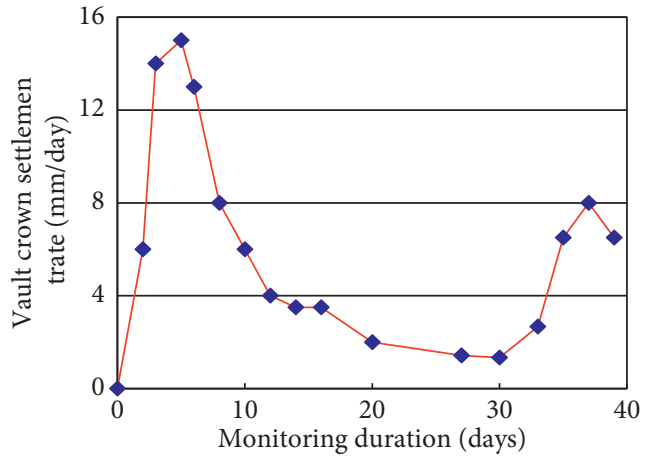

(b)

Figure 1: Vault crown settlement of the right tube at the stake of YK61 + 810 in Huangjiazhai Tunnel: (a) accumulated vault crown settlement with monitoring duration; (b) vault crown settlement rate with monitoring duration.

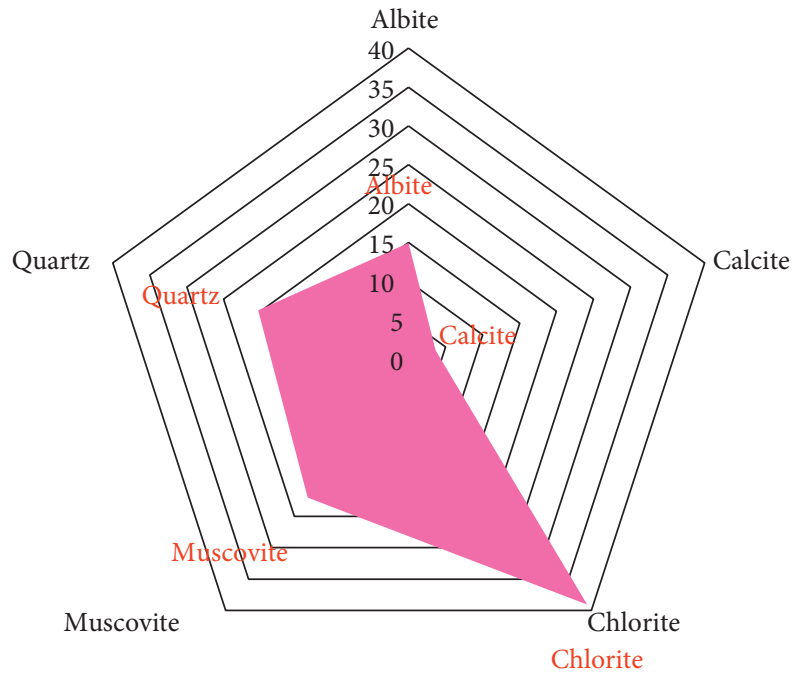

Figure 2: Mineral components.

strong water absorption ability due to mineral components of chlorite and muscovite.

2.2. Methods. The experimental study consists of macroscale mechanical tests and SEM analysis. To obtain mechanical properties of shale and provide basic information for numerical modelling, macroscale mechanical tests (uniaxial test, Brazilian disk test, and triaxial test) were performed on shales with various water contents. The three types of mechanical tests could give information under different conditions: (1) Uniaxial test applies a vertical load on the sample, which gives the rock a maximum principal compressive stress. Uniaxial strength and stiffness of the material are easily obtained. The uniaxial test was conducted on immersed samples. The failure characters of the samples with various immersion times could be observed from macroscopic and microscopic perspectives. (2) Brazilian disk test gives a vertical load on a lying cylinder sample. The rock is split due to tensile failure. The tensile strength was calculated for the dried and saturated samples. The failure characters were compared. (3) Triaxial test applies a confining pressure

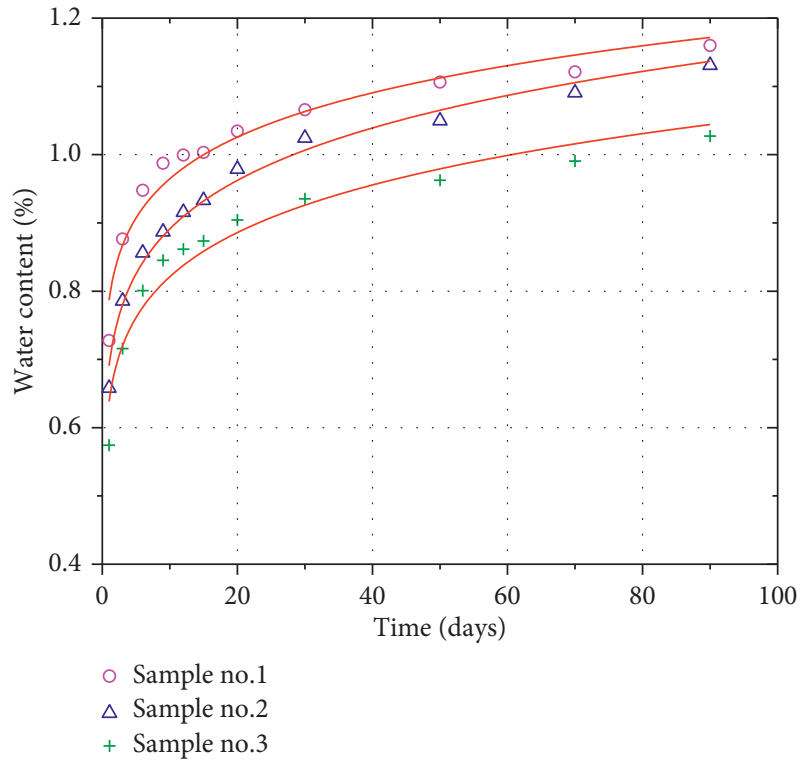

Figure 3: Variation of water content with time for the immersed samples.

followed by a deviatoric pressure. It could simulate the engineering stress state in an approximate way. Before tunnel is excavated, the rock is suppressed with a confining pressure. After excavation, a deviatoric stress is applied and the rock is destroyed. In the triaxial test, strength of dried and saturated samples under various confining pressure was obtained and compared. All the tests were done in controlled humidity room equipped with air condition. In each situation, 3 samples were tested and the most regular results were choice for analysis.

\section{Mechanical Test Results}

3.1. Uniaxial Compression Behavior. Uniaxial compression tests were carried out on shale samples immersed for 2 days, 15 days, 30 days, 50 days, 70 days, and 90 days, respectively. The tests were performed on RMT-150C rock mechanics test system in the Institute of Rock and Soil Mechanics, Chinese 
Academy of Sciences. The loading rate for the uniaxial test is $0.002 \mathrm{~mm} / \mathrm{s}$. Figure 4 shows the stress-strain curve of shale with different immersion times. In the initial stage of loading, shale is compressed with pore collapse. The slope of the curve is relatively low, but becomes steeper. With the continuous loading, the slope of the curve increases gradually followed by an elastoplastic deformation stage. When the shale reaches the peak strength, the stress decreases with a sudden drop. It means brittle failure occurs when the shale reaches its peak strength.

The peak strength is obtained as the maximum of the axial stress, and elastic modulus is the slope of the most linear part of the stress-strain curve. Figure 5 shows the evolution of peak strength and elastic modulus in uniaxial compression tests. At the beginning of the water immersion, the peak strength and modulus of elasticity drop rapidly. With increasing immersion time, the decreasing rate of the strength and stiffness gets smaller. For the sample without water immersion, the uniaxial strength and elastic modulus are $56.85 \mathrm{MPa}$ and $27.38 \mathrm{GPa}$, respectively. In contrast, the uniaxial strength and elastic modulus under the water immersion time of 90 days are $21.54 \mathrm{MPa}$ and $11.40 \mathrm{GPa}$, nearly dropped by more than half.

Softening coefficient is defined as the ratio of strength of water immersed rock to dried rock [37]:

$$
K=\frac{\sigma_{w}}{\sigma_{c}}
$$

where $K$ is the softening coefficient, $\sigma_{w}$ is the peak strength of water immersed samples, and $\sigma_{c}$ is the peak strength of dried samples. The softening coefficient reflects the water effect on mechanical properties. As seen from Figure 5, the softening coefficient is 0.38 at the immersion time of 90 days. Except the data scatter, in general, the shale gets smaller strength and larger deformation with a longer time of water immersion.

3.2. Tensile Behaviour in Brazilian Disk Test. Brazilian disk test was conducted on $\mathrm{RMT}-150^{\circ} \mathrm{C}$ test machine. The compressive load in the axial direction results in tensile stress in the middle of the sample. The tensile strength is smaller than the compressive strength in geomaterials, so the sample fails by tensile stress in Brazilian disk test. The loading rate for the uniaxial test is $0.05 \mathrm{kN} / \mathrm{s}$. The axial forceaxial deformation curve is shown in Figure 6.

The tensile strength may be calculated by the following formula based on elastic theory:

$$
\sigma_{t}=\frac{2 P}{D h \pi}
$$

where $\sigma_{t}$ is tensile strength in $\mathrm{MPa}, P$ is the maximum axial force in $\mathrm{N}, D$ is the diameter of the sample in $\mathrm{mm}$, and $h$ is the height of the sample in $\mathrm{mm}$. The diameter and height used in the Brazilian disk test in this study are $50 \mathrm{~mm}$ and $25 \mathrm{~mm}$, respectively. The average tensile strength of 3 samples for dried samples is $8.5 \mathrm{MPa}$, while $5.4 \mathrm{MPa}$ for saturated samples. The softening coefficient is 0.63 . So the tensile strength of the saturated samples decreases by $36 \%$ compared to the dried samples.
3.3. Triaxial Compression Behavior. Triaxial test was performed on the MTS testing system in the Institute of Rock and Soil Mechanics, Chinese Academy of Sciences. The loading rate for the triaxial test is $0.25 \mathrm{MP} / \mathrm{s}$. The stress-strain curves for saturated and dried samples are shown in Figure 7. Compared with dried samples, there is a remarkable compressive section at the beginning of loading for saturated samples, which is caused by pore collapse. After the pore collapse, there is a linear elastic section followed by a nonlinear elastoplastic section. The elastic modulus increases with increasing confining pressure. The water weakens the elastic modulus in saturated samples compared with the dried samples.

The average of the maximum principal stress at failure is shown in Figure 8. As seen, the triaxial compressive strength is affected by both water and confining pressure. Under a confining pressure of $10 \mathrm{MPa}$, the average strength of the dried sample and saturated sample is $118.4 \mathrm{MPa}$ and 89.2 $\mathrm{MPa}$, respectively. The softening coefficient is 0.75 . However, under a confining pressure of $20 \mathrm{MPa}$, the strength of the dried and saturated samples is $260.6 \mathrm{MPa}$ and 136.9 $\mathrm{MPa}$, respectively. The softening coefficient is 0.52 . In a whole, the peak strength of dried samples is larger than that of saturated samples under the same confining pressure. On the other hand, for the sample of the same water content, the peak strength increases with the confining pressure. It is also worth noting that based on the test data, the ratio of strength in dried samples to the saturated samples becomes larger as the confining pressure increases. The gap between the dried strength and saturated strength is $29.1 \mathrm{MPa}$ under a confining pressure of $10 \mathrm{MPa}$, while the gap is $123.7 \mathrm{MPa}$ under a confining pressure of $20 \mathrm{MPa}$.

3.4. A Numerical Case Study of Water Effect. The mechanical properties of shale are sensitive to water immersion. As seen from indoor test, a tunnel excavation could be numerically simulated based on the indoor test results. The parameters used in numerical modelling are determined through the following steps:

(1) The uniaxial strength and elastic parameters under various water immersion times are obtained. From equation (1), softening coefficient could be solved.

(2) The conventional triaxial strength of dried rock under various confining pressures is obtained with triaxial test.

(3) The tensile strength of dried rock is obtained with Brazilian disk test.

(4) Suppose that the softening coefficient in step 1 could also be applied for triaxial compressive loading condition and tensile strength. Then, the triaxial strength and tensile strength under various water immersion times could be solved based on equation (1).

(5) Based on the triaxial strength in step 4, the strength parameters, i.e., internal friction angle and cohesion, under various water immersion times could be solved from the following expression of Mohr-Coulomb criterion: 


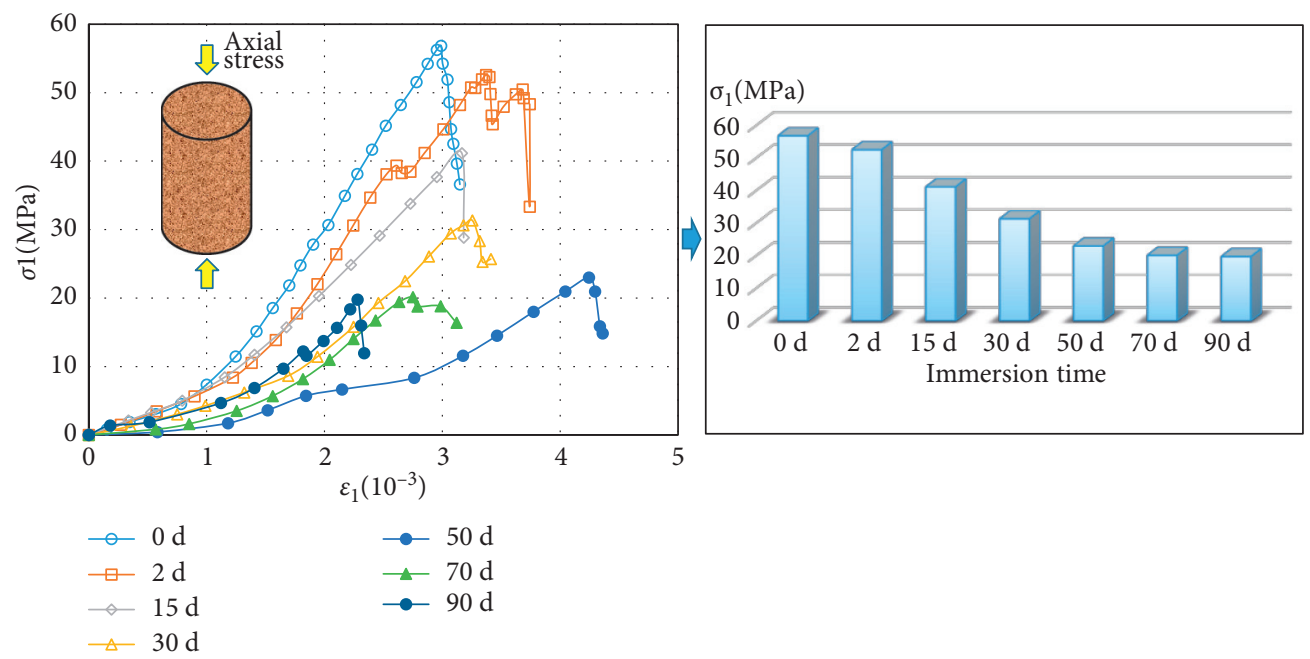

FIGURE 4: Stress-strain curve of shale with different immersion times under uniaxial compression.

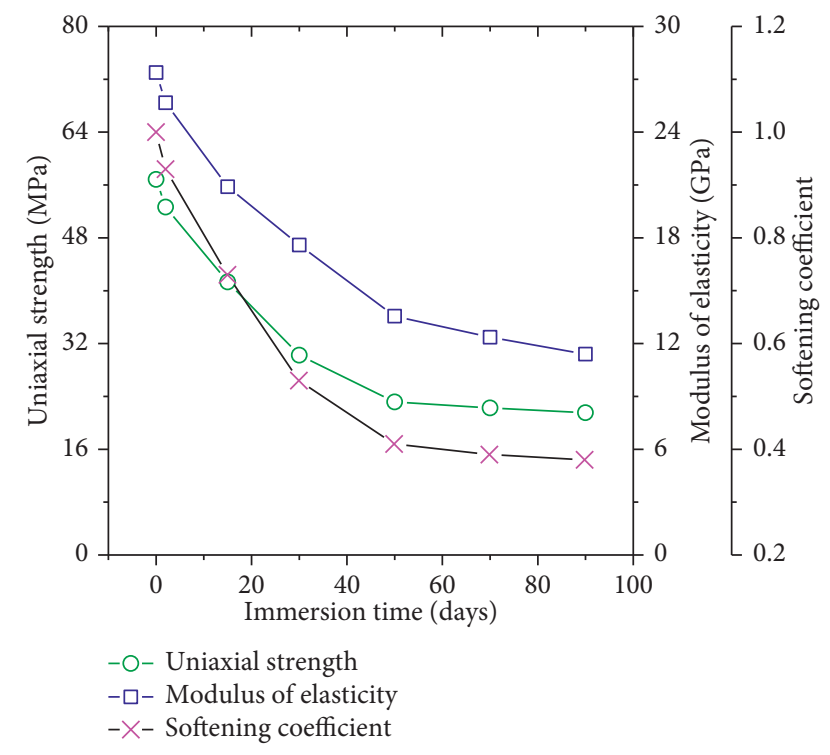

FIGURE 5: Uniaxial strength, elastic modulus, and softening coefficient under different immersion times.

$$
\sigma_{1}=\frac{1+\sin \varphi}{1-\sin \varphi} \sigma_{3}+2 c \frac{\cos \varphi}{1-\sin \varphi},
$$

where $\varphi$ and $c$ are the Mohr-Coulomb yield strength parameters, representing the internal friction angle and cohesion, respectively. The numerical study is conducted with the aid of FLAC3D software. The ideal elastoplastic model with Mohr-Coulomb criterion and tension cutoff is used. Unlike nonlinear models $[38,39]$, it is simple for calculations. The parameters are achieved from the above works and listed in Table 1. Poisson's ratio is 0.35 for all the circumstances. The initial geostress is determined based on in situ stress test results as $14.6 \mathrm{MPa}, 7.86 \mathrm{MPa}$, and $7.83 \mathrm{MPa}$, respectively. For safe excavation, the axis of the tunnel is consistent with the direction of the maximum principal stress. The minimum principal stress is self-weight stress.

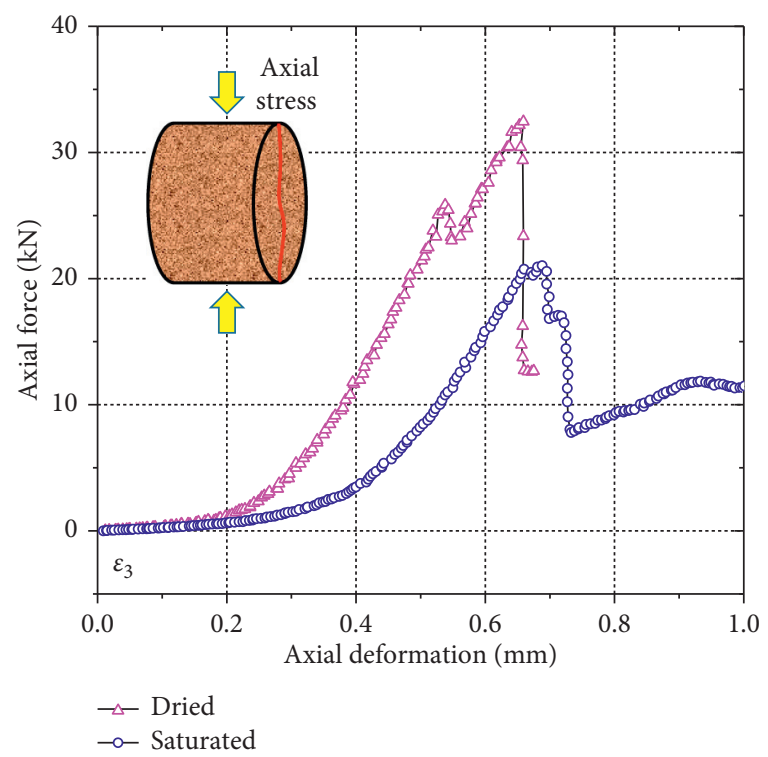

FIgURE 6: Axial force-axial deformation curve in Brazilian disk test.

It is assumed that the strength under various water contents in triaxial loading and Brazilian test could be calculated based on the uniaxial test. It is implicit that the softening coefficients in these tests are equivalent. To verify the assumption, the following data are used and compared in Table 2. The calculated tensile strength under 90 days of immersion time is $3.23 \mathrm{MPa}$ (see Table 1), and in the Brazilian test, the tensile strength is $5.4 \mathrm{MPa}$ for saturated samples. The calculated friction angle and cohesion under 90 days of immersion time are $36.57^{\circ}$ and $4.2 \mathrm{MPa}$ (see Table 1), and in the triaxial test, the friction angle and cohesion are 42.5 $\mathrm{MPa}$ and $7.17 \mathrm{MPa}$, respectively, for the saturated samples, which could be deduced from Figure 7. As seen in Table 2, the gaps in the data between the calculation and test are acceptable. Although the failure mechanism in these tests is different, the calculation method offers an alternative and 


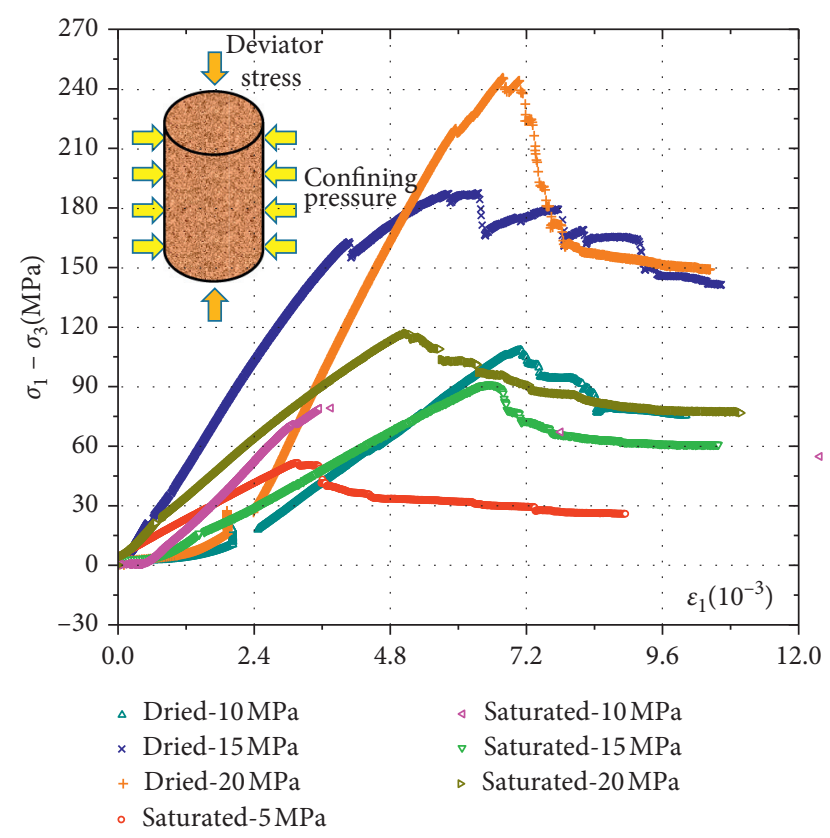

Figure 7: Stress-strain curves for dried and saturated samples in the triaxial test. Note that the stress in the legend is confining pressure.

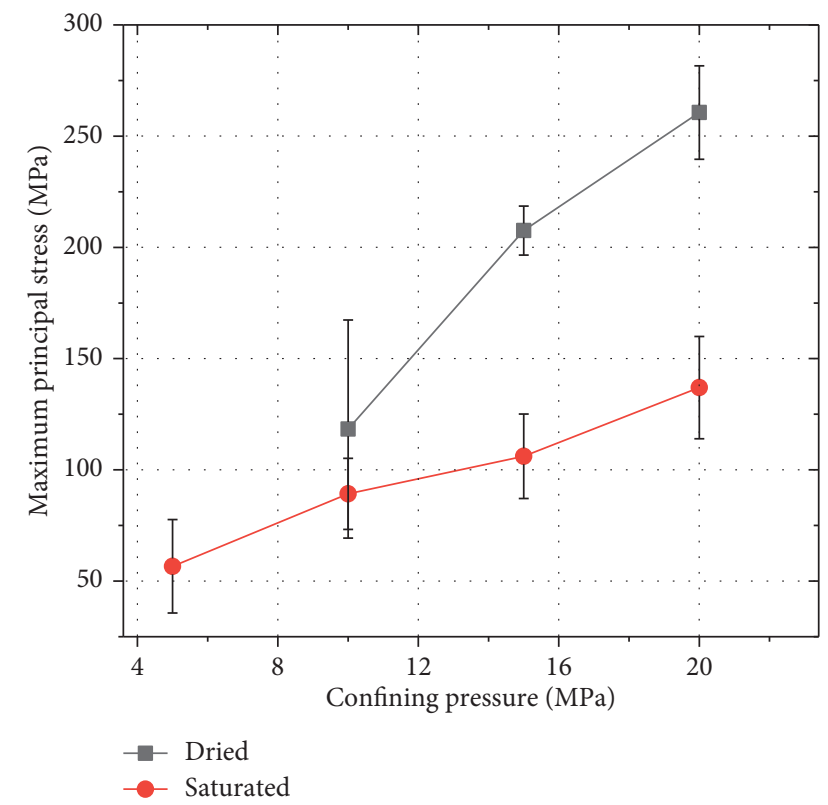

FIGURE 8: Variation of maximum principal stress with confining pressure in the triaxial test.

reasonable way to acquire parameters under various water contents.

To simulate the water effect on tunnel excavation, the surrounding rock is first adopted as a homogeneous material. The diameter of the tunnel is $6.5 \mathrm{~m}$. The block state and contour of $\mathrm{z}$-displacement in meters are recalculated after gravity balance. The results are shown in Figures 9(a)$9(\mathrm{~g})$. For the surrounding rock with a small value of moisture content, the plastic elements occur in the location between the directions of intermediate principal stress and minimum principal stress. With increasing water immersion time, the surrounding surface of the tunnel is gradually surrounded by plastic zones. In the contour of $\mathrm{z}$-displacement, there is a horizontal line in the middle of the tunnel representing zero z-displacement. The vault crown and tunnel floor both expand to the free surface, and the absolute values of $\mathrm{z}$-displacements are equal approximately. Another case of water influence is simulated, supposing the upper section of the surrounding rock is fully immersed by water due to rainfall compared with the lower section. The result is shown in Figure 9(h). The rainfall changes the mechanical properties of strata, resulting in the composite ground. It is like an up-soft/low-hard rock stratum with inhomogeneous characters [40, 41]. Different from the homogeneous surrounding rock, the plastic zones are mainly generated in the upper section, and the settlement of the vault crown is larger than $\mathrm{z}$-displacement of the tunnel floor. The $\mathrm{z}$-displacement of the upper surrounding rocks is no longer symmetrical with the surrounding rocks of lower section.

From a quantitative perspective, the volumes of plastic zones are calculated and the settlement of vault crown is determined. Figure 10 shows the volumes and settlements for comparison. The ratio in the figure means the ratio of plastic zone volumes or settlement under water immersed condition to dried condition. For the surrounding rocks with more moisture content, the settlement and plastic zones increase. The ratio of plastic zone volume and settlement under 90 days of water immersion is 8.35 and 2.4, respectively. The great water effect on plastic zones and deformation of the surrounding rock would cause serious problems in support.

It is worth noting that the role of numerical modelling is to study the rules of physical phenomena rather than accurate simulation. The aim of numerical investigation is to obtain acquaintance with the influence of water on tunnel excavation. Although the parameters of surrounding rocks are used from indoor test, the quantitative analysis of water effect could be obtained for consideration in surrounding rock support.

\section{Discussions}

Although several water-weakening mechanisms have been proposed, it is hard to find a universally acceptable explanation [42]. It has been recognized that the weakening of macroscopic mechanical properties of rocks is closely related to the changes in microstructures of rocks. To investigate the mechanism in the weakening effect of water on shale, SEM technique was conducted by Quanta 250 in the Institute of Rock and Soil Mechanics, Chinese Academy of Sciences. SEM slices were taken from the immersed samples without the mechanical tests. Figure 11 shows the scanned photos before mechanical test under various immersion times. The mechanism of water effect could be analyzed as follows:

(1) In the natural state, chlorite and muscovite as the main clay mineral in the shale develop well with the directional distribution of flakes. The mineral 
TABLE 1: Mechanical parameters in numerical modelling.

\begin{tabular}{lcccc}
\hline Immersion time (days) & Elastic modulus $(\mathrm{GPa})$ & Internal friction angle $\left(^{\circ}\right)$ & Cohesion $(\mathrm{MPa})$ & Tensile strength $(\mathrm{MPa})$ \\
\hline 0 & 27.38 & 55.52 & 6.83 & 8.5 \\
2 & 25.67 & 54.34 & 6.56 & 7.91 \\
15 & 20.9 & 50.1 & 5.81 & 6.21 \\
30 & 17.59 & 43.81 & 4.99 & 4.51 \\
50 & 13.55 & 38.33 & 4.34 & 3.49 \\
70 & 12.36 & 37.13 & 4.29 & 3.32 \\
90 & 11.4 & 36.57 & 4.2 & 3.23 \\
\hline
\end{tabular}

TABLE 2: Calculated value in the numerical modelling and test data.

\begin{tabular}{lccc}
\hline Method & Tensile strength $(\mathrm{MPa})$ & Internal friction angle $\left(^{\circ}\right)$ & Cohesion $(\mathrm{MPa})$ \\
\hline Calculation & 3.23 & 36.57 & 4.2 \\
Test & 5.4 & 42.5 & 7.17 \\
\hline
\end{tabular}

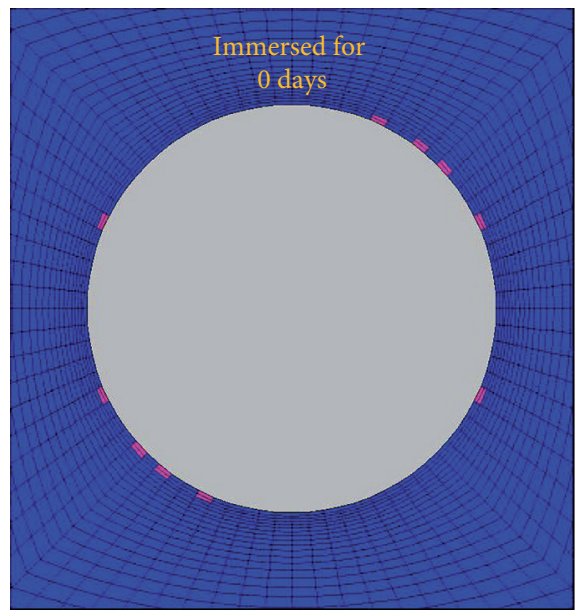

Block state
$\begin{aligned} & \text { None } \\ & \text { Shear-p }\end{aligned}$
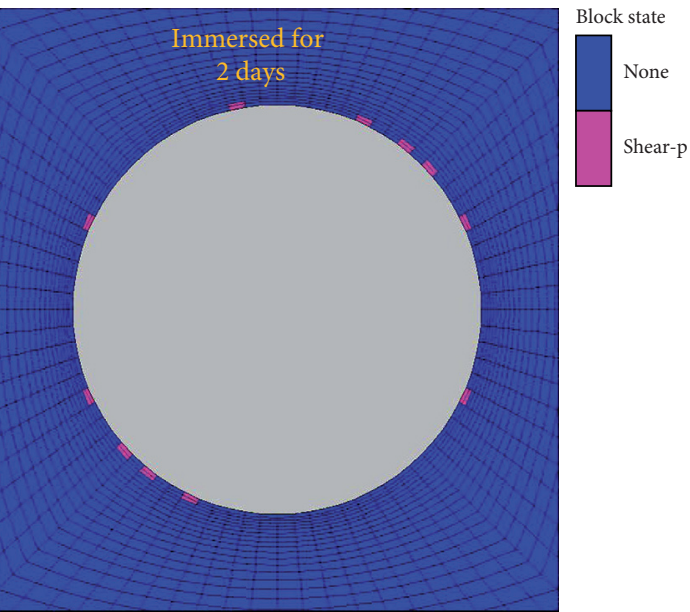

Contour Of Z-displacement

$\mathrm{M}$ agfac $=0.000 e+000$

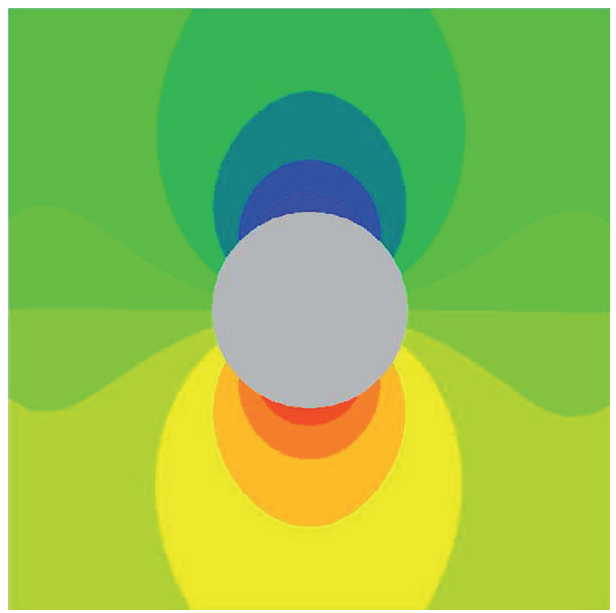

$2.8747 e-003$ to $-2.5000 e-003$

$-2.5000 e-003$ to $-2.0000 e-003$

$-2.0000 e-003$ to $-1.5000 e-003$

$-1.5000 e-003$ to $-1.0000 e-003$

$-1.0000 e-003$ to $-5.0000 e-004$

$-5.0000 e-004$ to $0.0000 e+000$

$0.0000 e+000$ to $5.0000 e-004$

$5.0000 e-004$ to $1.0000 e-003$

$1.0000 e-003$ to $1.5000 e-003$

$1.5000 e-003$ to $2.0000 e-003$

$2.0000 e-003$ to $2.5000 e-003$

$2.5000 e-003$ to $2.8684 e-003$

Interval $=5.0 e-004$

(a)

Contour Of Z-displacement

$\mathrm{M}$ agfac $=0.000 e+000$

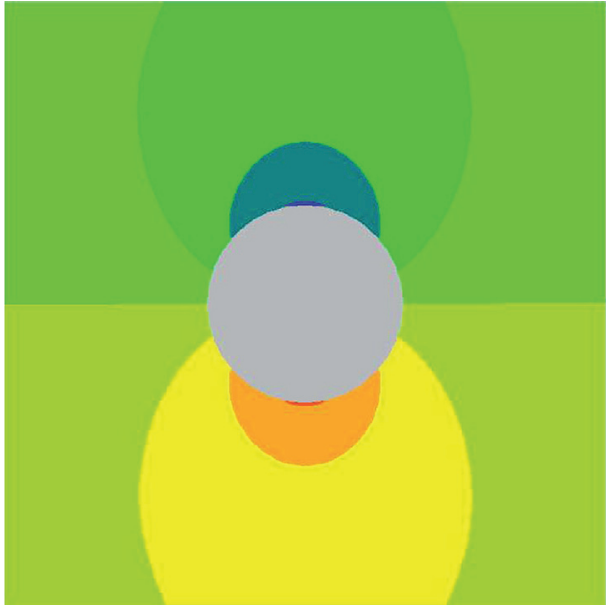

$3.0629 e-003$ to $-3.0000 e-003$

$3.0000 e-003$ to $-2.0000 e-003$

$-2.0000 e-003$ to $-1.0000 e-003$

$-1.0000 e-003$ to $0.0000 e+000$

$0.0000 e+000$ to $1.0000 e-003$

$0000 e-003$ to $2.0000 e-003$

$2.0000 e-003$ to $3.0000 e-003$

$3.0000 e-003$ to $3.0629 e-003$

Interval $=1.0 e-003$

(b)

Figure 9: Continued. 

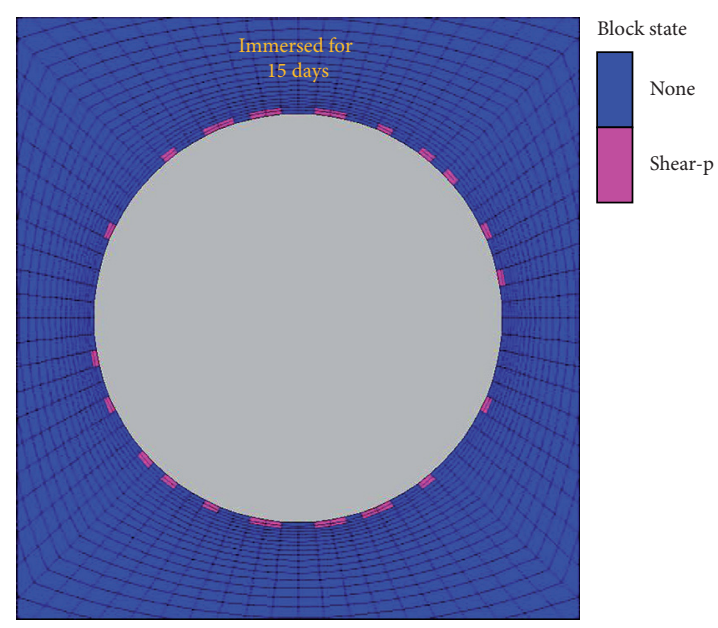

Block state

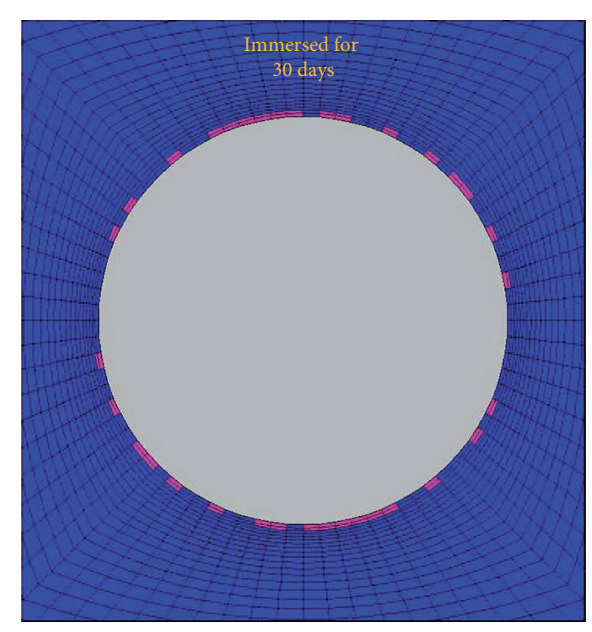

\begin{tabular}{l|l} 
None \\
Shear-p
\end{tabular}

(c)

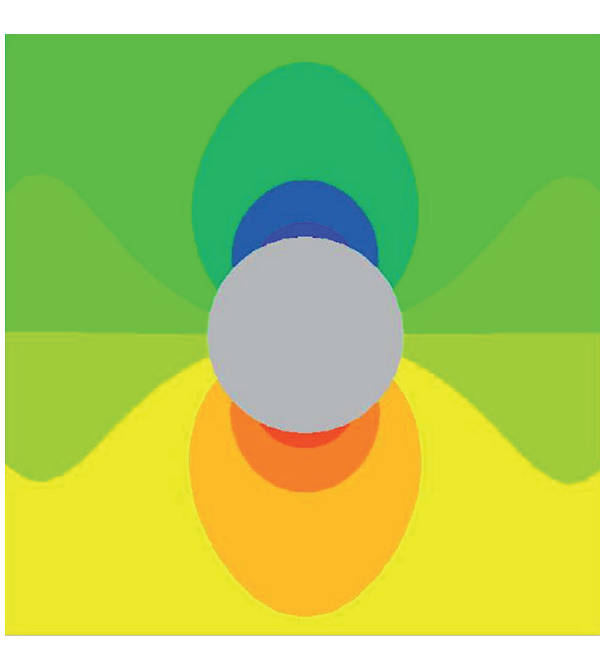

(d)
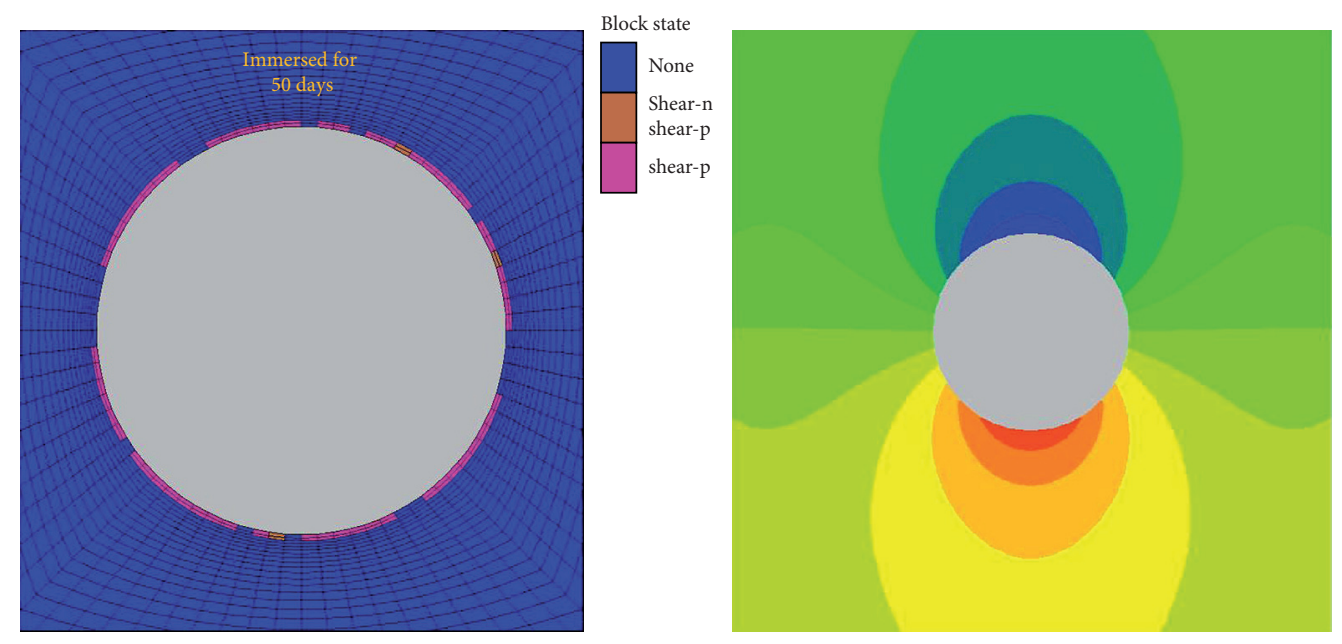

Contour Of $Z$-displacement

$\mathrm{M}$ agfac $=0.000 e+000$

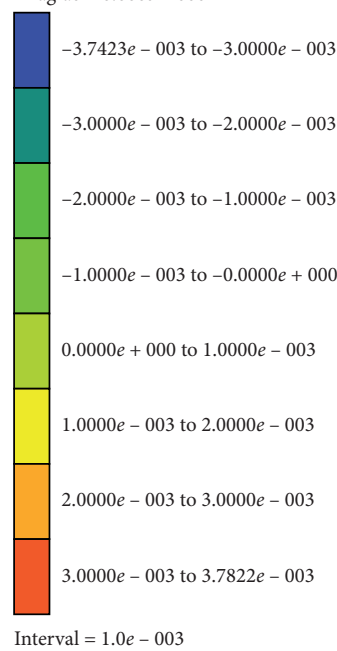

Interval $=1.0 e-003$

\section{Contour Of Z-displacement}

$\mathrm{M}$ agfac $=0.000 e+000$

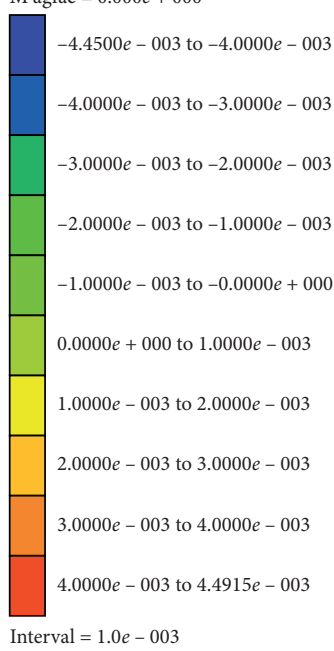

Contour Of $Z$-displacement

$\mathrm{M}$ agfac $=0.000 e+000$

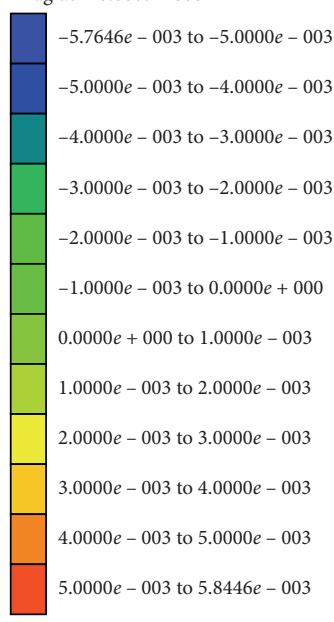

Interval $=1.0 e-003$

(e)

Figure 9: Continued. 

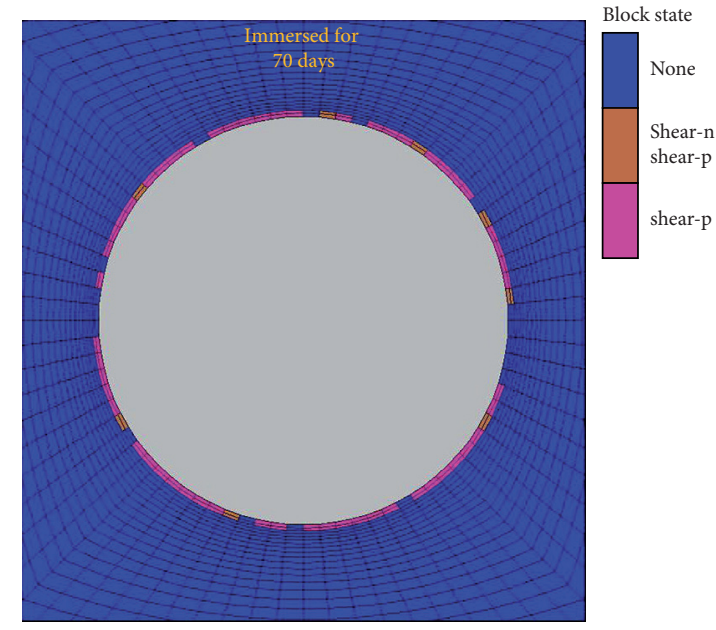

\section{P.}

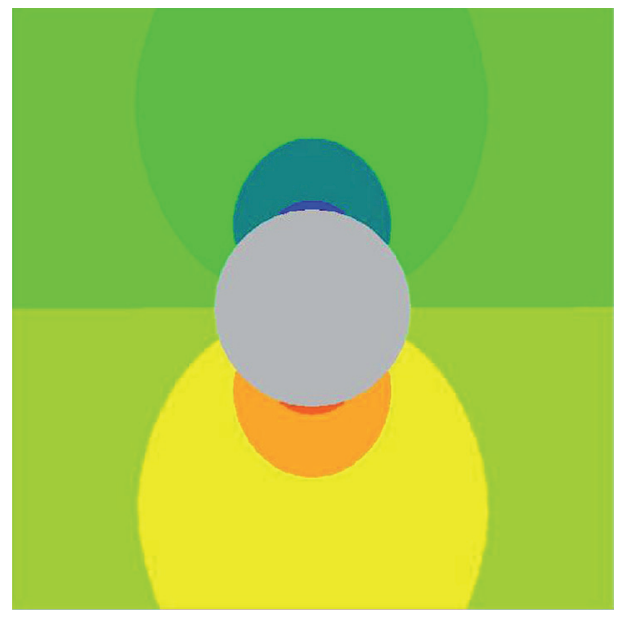

Contour Of $Z$-displacemen

$\mathrm{M}$ agfac $=0.000 e+000$

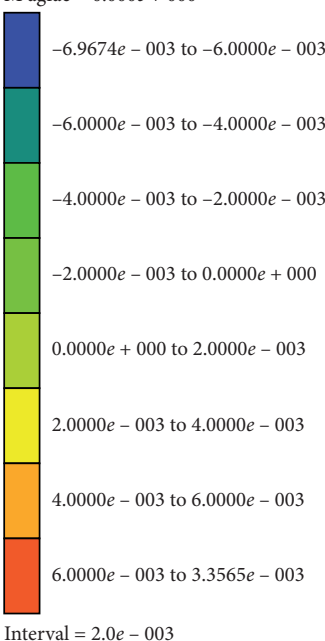

(f)

Contour Of $Z$-displacement

Block state

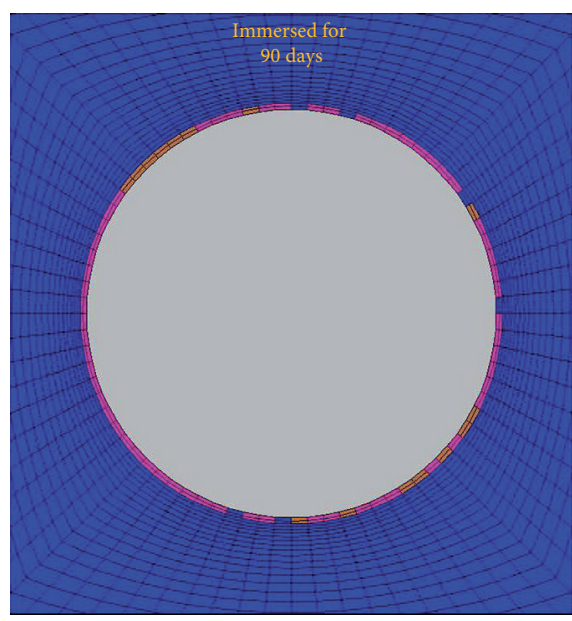

$\mathrm{M}$ agfac $=0.000 e+000$
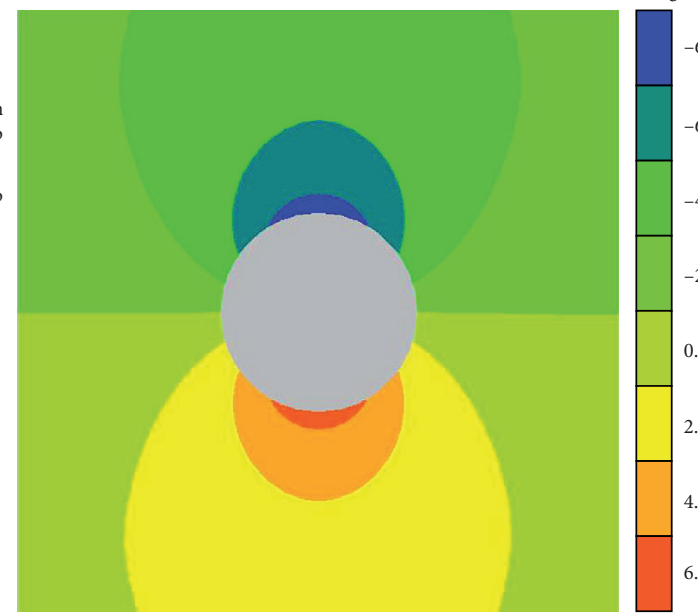

$-6.9239 e-003$ to $-6.0000 e-003$

$-6.0000 e-003$ to $-4.0000 e-003$

$-4.0000 e-003$ to $-2.0000 e-003$

$-2.0000 e-003$ to $0.0000 e+000$

$0.0000 e+000$ to $2.0000 e-003$

$2.0000 e-003$ to $4.0000 e-003$

$4.0000 e-003$ to $6.0000 e-003$

$6.0000 e-003$ to $6.8780 e-003$

(g)

Figure 9: Continued. 

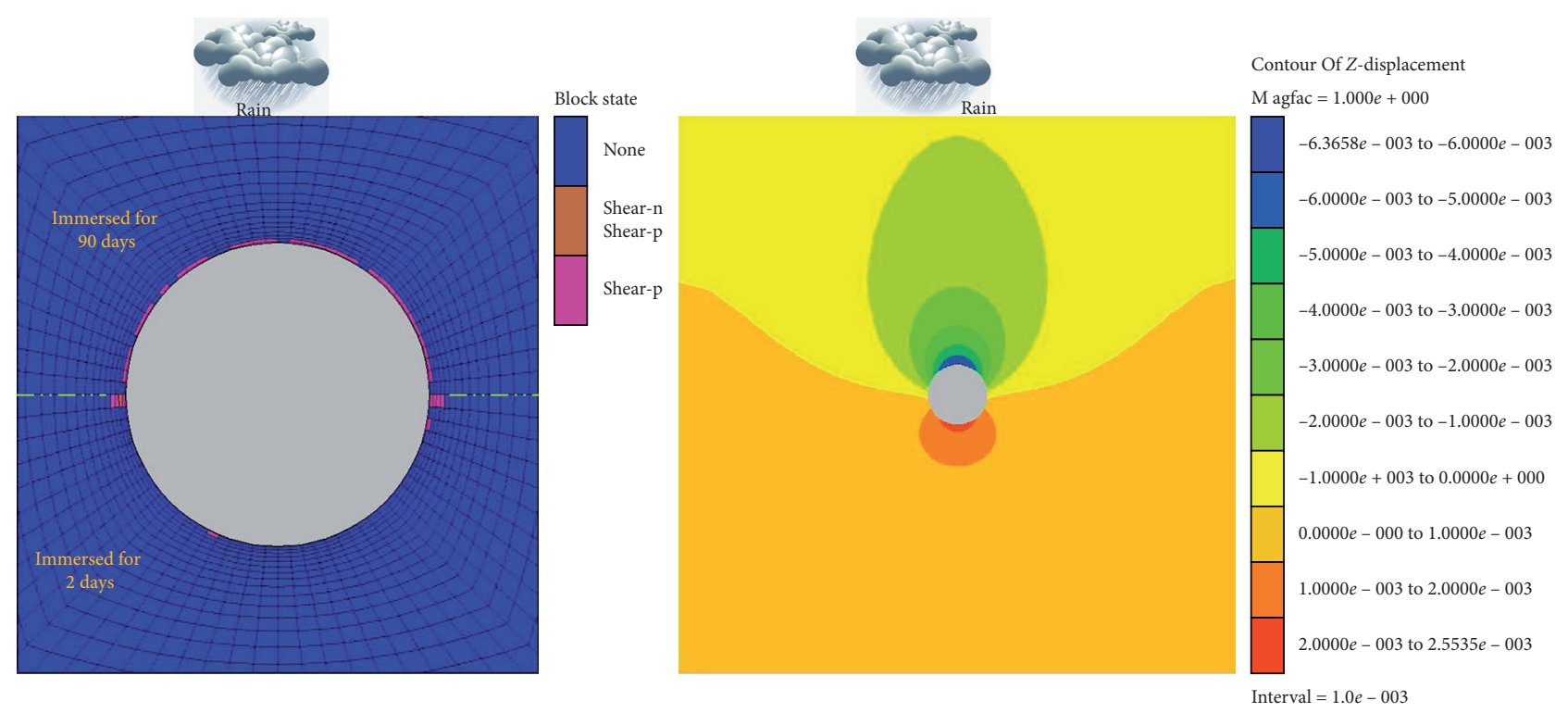

(h)

FIGURE 9: Block state and contour of z-displacement in the surrounding rock: (a) under 0 days of water immersion; (b) under 2 days of water immersion; (c) under 15 days of water immersion; (d) under 30 days of water immersion; (e) under 50 days of water immersion; (f) under 70 days of water immersion; ( $\mathrm{g}$ ) under 90 days of water immersion; (h) under rainfall circumstance with upper strata immersed for 90 days and lower strata immersed for 2 days.

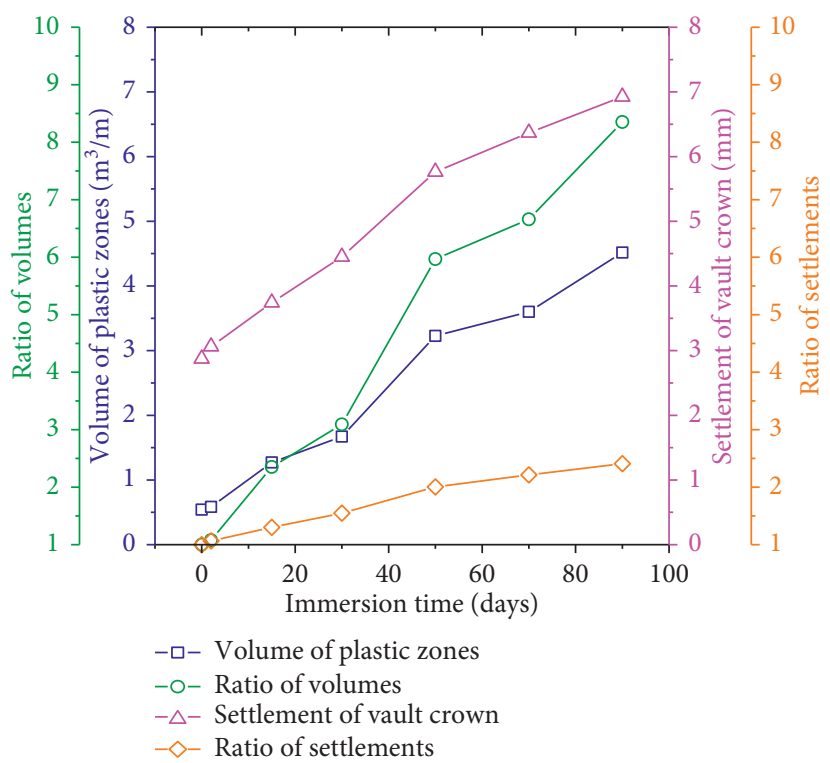

Figure 10: Volume of plastic zones and settlement of vault crown under various immersion times.

particles are cemented with chlorite, quartz, etc. The linkage between particles is in the form of surface-tosurface contact. In such contact, the microstructure is dense due to few pores and cracks.

(2) After 2 days of water immersion, the flakes begin to peel off under the influence of water. The peeled off mineral particles are about $8 \mu \mathrm{m}$ in length. At the same time, the connection between particles is still mainly in the form of surface-to-surface contact. However, as more mineral particles are dispersed and peeled off, the number of point-to-surface contact increases. In such case, the microstructure becomes loose.

(3) After 20 days of water immersion, water enters the interior microstructure and pores. Chlorite expands under the effect of water. Due to the expansion, the internal structure is gradually destroyed. The flake particles are dispersed into smaller slices, which are about $3 \mu \mathrm{m}$ in length. The connection between particles changes into point-to-surface contact. With 


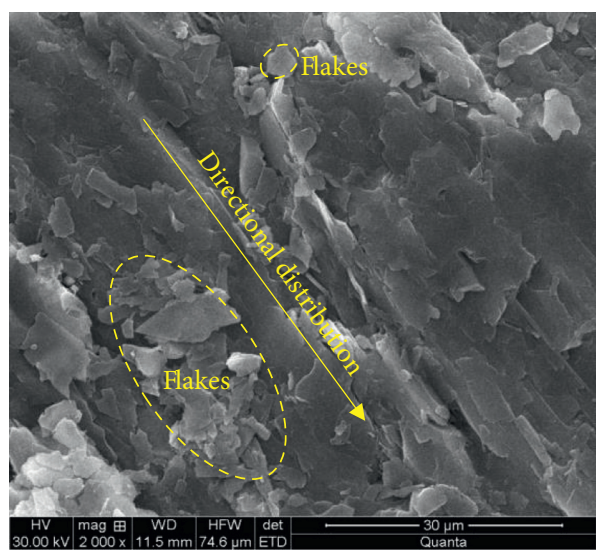

(a)

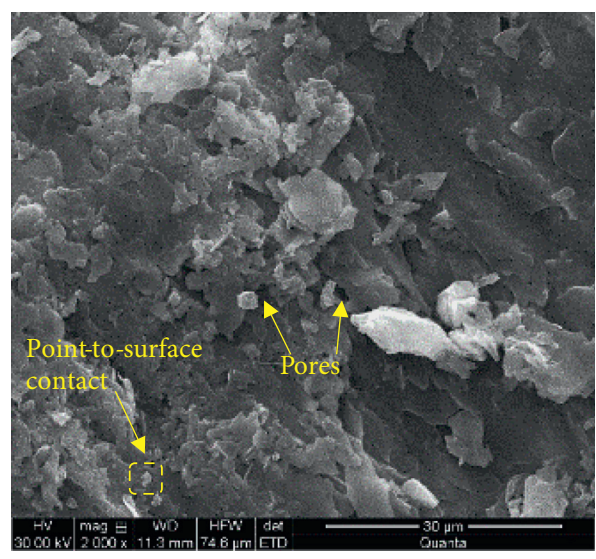

(c)

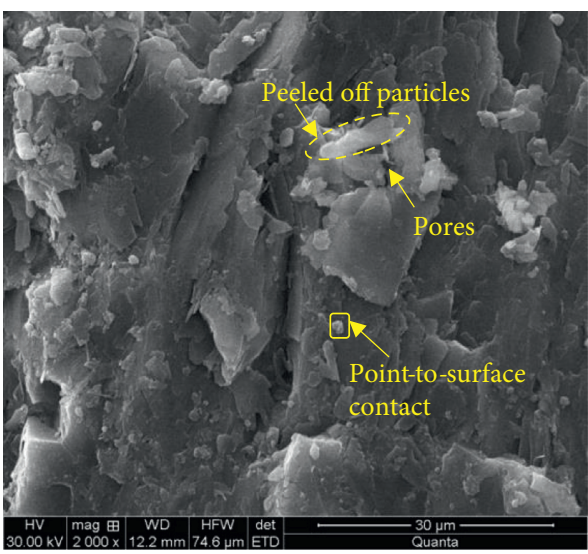

(b)

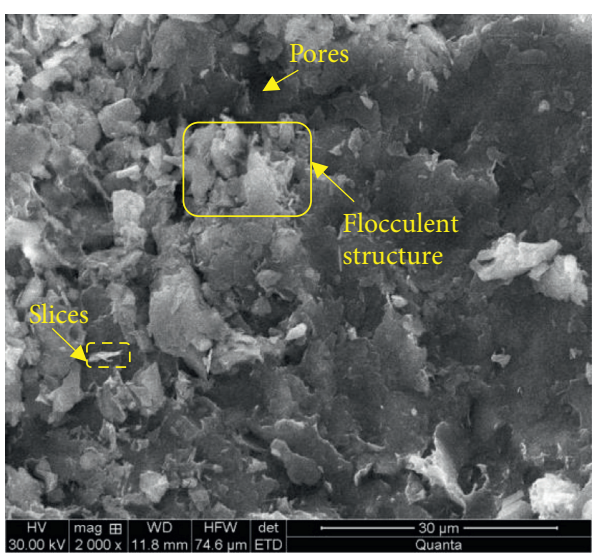

(d)

FigURE 11: Microstructure of shale under various water immersion times: (a) 0 days; (b) 2 days; (c) 20 days; (d) 50 days.

further destruction of cementation between minerals, the pores and cracks increase.

(4) After 50 days of water immersion, the shale microstructure is further destroyed. The cementation between minerals becomes weaker. Parts of clay particles form a flocculent structure. The formation of the flocculent structure further destroys the original structure and cementation.

Geomaterials generally consist of particles and pores. When clay particles swell in water, pore volume increases as well [43]. There is a charge in the water, which may be called solution [44]. The interface between a charged surface and an aqueous electrolyte solution is known as the electric double layer [45]. The negative charge forms one half of the electric double layer, and a net positive charge in the solution forms the other half of the electric double layer. The thickness of the electric double layer is formulated as follows [46]:

$$
\kappa=\sqrt{\frac{8 \pi z^{2} \epsilon^{2} n_{0 i}}{D D_{0} k T}}
$$

where $\kappa$ is a measure of the reciprocal thickness of the diffuse double layer, $z$ is the absolute value of the valence of an ion, $\epsilon$ is the charge on a single univalent cation, $n_{0 i}$ is the number of ions of type $X_{\mathrm{i}}$ in a unit volume of solution measured at a point remote from the double layer, $D$ is dielectric constant, $D_{0}$ is diabattivity of free space, $k$ is Boltzmann's constant, and $T$ is absolute temperature.

The concept of the electric double layer is introduced and used to illustrate the effect of water on shale from a microscopic perspective. As the immersion time increases, water enters the volume of shale and $n_{0 i}$ decreases. From equation (4) $\kappa$ would decrease, and the thickness of the double layer would increase. In such case, the distance between particles increases. The cohesive strength would decrease and would induce cracks. Corresponding to the microscale results, the macroscale failure morphology is shown in Figure 12.

Under water effect, the cohesion of shale becomes weaker. The strength gets smaller with the immersion time. Meanwhile, the cracks and pores generate. In such case, the shale is easy to get larger deformation and decreasing stiffness. In the uniaxial compressive state, the shale specimens fail mainly along the bedding surface or at a small angle with the bedding surface. It could be obviously observed that with the increase of water immersion time, more failure planes penetrate. It is the evidence of the waterweakening effect from a macroscopic viewpoint.

Meanwhile, in the triaxial test, the saturated shale fails mainly along an inclined plane. There are not so many 


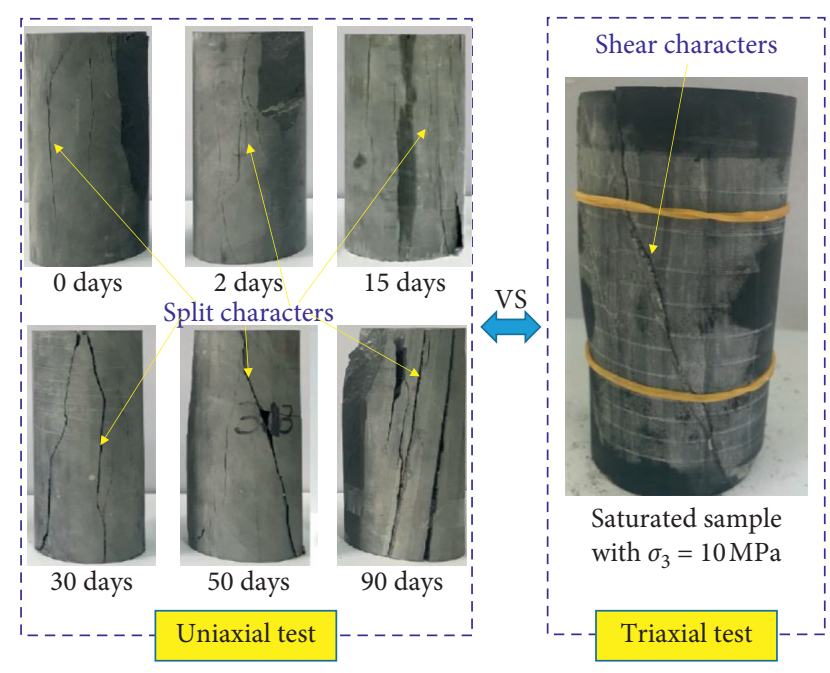

FIGURE 12: Failure morphology of shale samples in the uniaxial test and triaxial test.

fractures as generated in the uniaxial test. It could be inferred that the confining pressure works. As the confining pressure acts at the surface of the sample, lateral deformation is restrained. The shale could bear more loading stress. Therefore, timely support and confining pressure supply is an effective and essential approach for construction [47, 48].

This study is developed based on the research by Zheng et al. [34], which was conducted at the geological survey stage before construction. The studies both focus on the shale in Huangjiazhai Tunnel in China, for the serious condition and important problem during excavation. In Zheng et al.'s study, the main contents are two respects: uniaxial test and microscale study. The microscale study was through SEM observation and description, while lacking theoretical analysis. Considering the insufficiency, in our study, kinds of mechanical tests were investigated, including uniaxial test, triaxial test, and Brazilian test. Through these tests, the water-weakening effect was fully studied. On microscale, SEM results were analyzed with the theory of the electric double layer. The failure mechanism of rock block in water was elaborated on both macroscopic and microscopic scales. A numerical case study of tunnel excavation under water condition was simulated. Therefore, more technical investigations and analysis (including test, theoretical analysis, and numerical simulation) were integrated in our paper. The comprehensive results in our paper offered suggestions and benefited the construction in shale strata.

\section{Conclusions}

(1) Under uniaxial compressive stress, water has an obvious influence on the peak strength and elastic modulus with a rapid drop at the beginning of the water immersion. With immersion time increases, the reduction of the strength and stiffness gets moderate. The average uniaxial compressive strength and modulus of saturated shale could be reduced by $62 \%$ and $58 \%$.
(2) With the Brazilian disk test, the tensile strength of the saturated samples is lower than that of the dried samples. The tensile strength of the saturated sample decreases by $36 \%$ under the effect of water.

(3) In the triaxial test, there is a remarkable pore collapse at the beginning of loading for saturated samples. The mechanical behavior is affected by both water and confining pressure. The peak strength increases with less water content and increasing confining pressure. The ratio of strength in dried samples to the saturated samples becomes larger as the confining pressure increases. The softening coefficient is 0.75 and 0.52 under confining pressures of $10 \mathrm{MPa}$ and $20 \mathrm{MPa}$ approximately.

(4) Based on macroscale experiment, the parameters used in numerical modelling were determined. In the evaluation of water effect on tunnel excavation with homogeneous surrounding rock, plastic zones and $\mathrm{z}$-displacement increase with increasing water immersion time. The vault crown and tunnel floor both expand to the free surface, and the absolute values of z-displacements are equal approximately. The simulation of rainfall impact shows that plastic zones are mainly generated in the upper section, and the settlement of vault crown is larger than $\mathrm{z}$-displacement of the tunnel floor.

(5) With the increase of immersion time, more mineral particles are dispersed and peeled off. The flake particles are dispersed into smaller slices, and the connection between mineral particles gradually changes into point-to-surface contact. The microstructure becomes looser, and pores and cracks generate. The electric double layer was introduced and used for illustrating the effect of water on shale. The thickness of the double layer increases with the increase of water immersion time. From macroscale morphology, the number of penetrating planes increases, while confining pressure could inhibit the generation of cracks. It is essential to perform timely support and supply confining pressure in construction.

\section{Data Availability}

The data used to support the findings of this study are available from the corresponding author upon request.

\section{Conflicts of Interest}

The authors declare no conflicts of interest.

\section{Acknowledgments}

This work was supported by the National Natural Science Foundation of China (NSFC) (Grant nos. 51704097, 51808197, 51804100, and U1810203), Key Research and Development Program of Henan Province, China (Grant nos. 202102310244 and 202102310289), Research and Development Project of CCCC (Grant nos. KJFZ-2017-073 and 
KJFZ-2018-040), Science Foundation of Henan Polytechnic University (Grant no. B2016-65) and Annual Social Science Projects of Henan Polytechnic University (Grant no. SKND2019-12).

\section{References}

[1] Z. Li, D. D. Zhang, and S. Zhao, "Loading and unloading test of hard rock and its elastoplastic damage coupling model," Acta Geotechnica Slovenica, vol. 15, no. 2, pp. 38-46, 2018.

[2] P. Wang, L. S. Jiang, P. Q. Zheng, G. P. Qin, and C. Zhang, "Inducing mode analysis of rock burst in fault-affected zone with a hard-thick stratum occurrence," Environmental Earth Science, vol. 78, p. 467, 2019.

[3] S. C. Hu, Y. L. Tan, H. Zhou et al., "Anisotropic modeling of layered rocks incorporating planes of weakness and volumetric stress," Energy Science and Engineering, vol. 8, no. 3, pp. 1-15, 2019.

[4] Z. Li, H. Zhou, Y. Jiang, D. Hu, and C. Zhang, "Methodology for establishing comprehensive stress paths in rocks during hollow cylinder testing," Rock Mechanics and Rock Engineering, vol. 52, no. 4, pp. 1055-1074, 2019.

[5] Q. Yin, R. Liu, H. Jing, H. Su, L. Yu, and L. He, "Experimental study of nonlinear flow behaviors through fractured rock samples after high-temperature exposure," Rock Mechanics and Rock Engineering, vol. 52, no. 9, pp. 2963-2983, 2019.

[6] H. Su, H. Jing, L. Yu, Q. Yin, and G. Han, "Mode I fracture behaviour of sandstone after heat treatment," Géotechnique Letters, vol. 7, no. 1, pp. 47-52, 2017.

[7] H. Su, H. Jing, Q. Yin, L. Yu, Y. Wang, and X. Wu, "Strength and deformation behaviors of veined marble specimens after vacuum heat treatment under conventional triaxial compression," Acta Mechanica Sinica, vol. 33, no. 5, pp. 886-898, 2017.

[8] Z. Li, H. X. Liu, Z. L. Dun, L. W. Ren, and J. J. Fang, "Grouting effect on rock fracture using shear and seepage assessment," Construction and Building Materials, vol. 242, Article ID 118131, 2020.

[9] L. Shi, B. Zhang, H.-X. Wang, H.-J. Zhang, Z.-H. Peng, and J.-Y. Li, "Investigation on the causes of abnormal increase of water inflow in underground water-sealed storage system," Tunnelling and Underground Space Technology, vol. 87, pp. 174-186, 2019.

[10] P. Colback and B. Wild, "The influence of moisture content on the compressive strength of rocks," in Proceeding of the $3 \mathrm{rd}$ Canadian symposium on Rock Mechanics, pp. 65-83, Toronto, Canada, January 1965.

[11] B. Vásárhelyi, "Statistical analysis of the influence of water content on the strength of the miocene limestone," Rock Mechanics and Rock Engineering, vol. 38, no. 1, pp. 69-76, 2005.

[12] M. A. Rajabzadeh, Z. Moosavinasab, and G. Rakhshandehroo, "Effects of rock classes and porosity on the relation between uniaxial compressive strength and some rock properties for carbonate rocks," Rock Mechanics and Rock Engineering, vol. 45, no. 1, pp. 113-122, 2012.

[13] V. Gajic, V. Matovic, N. Vasic, and D. Sreckovic-Batocanin, "Petrophysical and mechanical properties of the Struganik limestone (Vardar zone, Western Serbia)," Geoloski Anali Balkanskog Poluostrva, vol. 72, no. 72, pp. 87-100, 2011.

[14] R. L. Mann and I. Fatt, "Effect of pore fluids on the elastic properties of sandstone," Geophysics, vol. 25, no. 2, pp. 433444,1960
[15] M. L. Talesnick, Y. H. Hatzor, and M. Tsesarsky, "The elastic deformability and strength of a high porosity, anisotropic chalk," International Journal of Rock Mechanics and Mining Sciences, vol. 38, no. 4, pp. 543-555, 2001.

[16] Z. A. Erguler and R. Ulusay, "Water-induced variations in mechanical properties of clay-bearing rocks," International Journal of Rock Mechanics and Mining Sciences, vol. 46, no. 2, pp. 355-370, 2009.

[17] K. Hashiba and K. Fukui, "Effect of water on the deformation and failure of rock in uniaxial tension," Rock Mechanics and Rock Engineering, vol. 48, no. 5, pp. 1751-1761, 2015.

[18] O. Ojo and N. Brook, "The effect of moisture on some mechanical properties of rock," Mining Science and Technology, vol. 10, no. 2, pp. 145-156, 1990.

[19] H. Karakul and R. Ulusay, "Empirical correlations for predicting strength properties of rocks from p-wave velocity under different degrees of saturation," Rock Mechanics and Rock Engineering, vol. 46, no. 5, pp. 981-999, 2013.

[20] N. S. Parate, "Influence of water on the strength of limestone," International Journal of Rock Mechanics and Mining Sciences and Geomechanics Abstracts, vol. 11, no. 6, p. 120, 1974.

[21] F. G. Bell, "The physical and mechanical properties of the fell sandstones, Northumberland, England," Engineering Geology, vol. 12, pp. 1-29, 1978.

[22] W. Hua, J. Li, S. Dong, and X. Pan, "Experimental study on mixed mode fracture behavior of sandstone under water-rock interactions," Processes, vol. 7, no. 2, p. 70, 2019.

[23] C. G. Dyke and L. Dobereiner, "Evaluating the strength and deformability of sandstones," Quarterly Journal of Engineering Geology and Hydrogeology, vol. 24, no. 1, pp. 123-134, 1991.

[24] L. S. Burshtein, "Effect of moisture on the strength and deformability of sandstone," Soviet Mining Science, vol. 5, no. 5, pp. 573-576, 1969.

[25] M. Lal, "Shale stability: drilling fluid interaction and shale strength," SPE Asia Pacific Oil and Gas Conference and Exhibition, Society of Petroleum Engineers, Jakarta, Indonesia, pp. 20-22, 1999.

[26] C. M. White, D. H. Smith, K. L. Jones et al., "Sequestration of carbon dioxide in coal with enhanced coalbed methane RecoveryA review," Energy \& Fuels, vol. 19, no. 3, pp. 659-724, 2005.

[27] A. R. Jumikis, Some Engineering Aspects of Brunswick Shale, 1st Congress of the International Society of Rock Mechanics, Lisbon, Portugal, 1966.

[28] M. Gutierrez, L. E. Øino, and K. Høeg, "The effect of fluid content on the mechanical behaviour of fractures in chalk," Rock Mechanics and Rock Engineering, vol. 33, no. 2, pp. 93-117, 2000.

[29] M. R. D. Silva, C. Schroeder, and J. C. Verbrugge, "Unsaturated rock mechanics applied to a low-porosity shale," Engineering Geology, vol. 97, no. 2, pp. 42-52, 2008.

[30] M. L. Lin, F. S. Jeng, L. S. Tsai, and T. H. Huang, "Wetting weakening of tertiary sandstones-microscopic mechanism," Environmental Geology, vol. 48, no. 2, pp. 265-275, 2005.

[31] X. Chen, P. Eichhubl, J. E. Olson, and T. A. Dewers, "Salinity, $\mathrm{pH}$, and temperature controls on fracture mechanical properties of three shales and their implications for fracture growth in chemically reactive fluid environments," Geomechanics for Energy and the Environment, vol. 21, Article ID 100140, 2020.

[32] X. Chen, P. Eichhubl, J. E. Olson, and T. A. Dewers, "Effect of water on fracture mechanical properties of shales," Journal of Geophysical Research: Solid Earth, vol. 124, no. 3, pp. 24282444, 2019. 
[33] X. Chen, P. Eichhubl, and J. E. Olson, "Effect of water on critical and subcritical fracture properties of Woodford shale," Journal of Geophysical Research: Solid Earth, vol. 122, no. 4, pp. 2736-2750, 2017.

[34] X. Q. Zheng, J. Liu, K. Bian, S. G. Liu, Z. P. Liu, and F. Ai, "Softening micro-mechanism and mechanical properties of water-saturated shale in Northwestern Hubei," Rock and Soil Mechanics, vol. 38, no. 7, pp. 2022-2028, 2017.

[35] G. Chen, T. Li, W. Wang, Z. Zhu, Z. Chen, and O. Tang, "Weakening effects of the presence of water on the brittleness of hard sandstone," Bulletin of Engineering Geology and the Environment, vol. 78, no. 3, pp. 1471-1483, 2019.

[36] G. Chen, T. Li, F. Guo, and Y. Wang, "Brittle mechanical characteristics of hard rock exposed to moisture," Bulletin of Engineering Geology and the Environment, vol. 76, no. 1, pp. 219-230, 2017.

[37] G. Chen, Y. Shi, F. Ji, T. Li, J. Wang, and Z. Wang, "Corrosion investigation of groundwater for underground tunnel," $\mathrm{Di}$ saster Advances, vol. 6, pp. 228-235, 2013.

[38] Z. Li, H. Zhou, D. Hu, and C. Zhang, "Yield criterion for rocklike geomaterials based on strain energy and CMP model," International Journal of Geomechanics, vol. 20, Article ID 04020013, 2010.

[39] H. Tu, C. Qiao, and Z. Han, "Elastic-brittle-plastic analysis of the radial subgrade modulus for a circular cavity based on the generalized nonlinear unified strength criterion," Tunnelling and Underground Space Technology, vol. 71, pp. 623-636, 2018.

[40] H. Tu, H. Zhou, C. Qiao, and Y. Gao, "Excavation and kinematic analysis of a shallow large-span tunnel in an up-soft/ low-hard rock stratum," Tunnelling and Underground Space Technology, vol. 97, Article ID 103245, 2020.

[41] P. Wang, H. Jia, and P. Zheng, "Sensitivity analysis of bursting liability for different coal-rock combinations based on their inhomogeneous characteristics," Geomatics, Natural Hazards and Risk, vol. 11, no. 1, pp. 149-159, 2020.

[42] V. Eeckhout, "The Mechanisms of strength reduction due to moisture in coal mine shales," International Journal of Rock Mechanics and Mining Sciences, vol. 13, no. 2, pp. 61-67, 1976.

[43] L. A. G. Aylmore and J. P. Quirk, "Swelling of clay-water systems," Nature, vol. 183, no. 4677, pp. 1752-1753, 1959.

[44] D. A. Laird, "Influence of layer charge on swelling of smectites," Applied Clay Science, vol. 34, no. 4, pp. 74-87, 2006.

[45] N. T. Skipper, M. V. Smalley, G. D. Williams, A. K. Soper, and C. H. Thompson, "Direct measurement of the electric doublelayer structure in hydrated lithium vermiculite clays by neutron diffraction," The Journal of Physical Chemistry, vol. 99, no. 39, pp. 14201-14204, 1995.

[46] D. C. Grahame, "The electrical double layer and the theory of electrocapillarity," Chemical Reviews, vol. 41, no. 3, pp. 441-501, 1947.

[47] H. Wang, C. Jiang, P. Zheng, W. Zhao, and N. Li, "A combined supporting system based on filled-wall method for semi coal-rock roadways with large deformations," Tunnelling and Underground Space Technology, vol. 99, Article ID 103382, 2020.

[48] C. X. Wang, B. T. Shen, and J. T. Chen, "Compression characteristics of filling gangue and simulation of mining with gangue backfilling: an experimental investigation," Geomechanics and Engineering, vol. 20, no. 6, pp. 485-495, 2020. 